\title{
Um estudo sobre a população da Capitania do Rio Grande com ênfase na escravidão negra e indígena no contexto da Guerra dos Bárbaros (1681-1714)
}

\section{A study on the population of the Captaincy of Rio Grande with emphasis on black and indigenous slavery in the context of the Barbarian War (1681-1714)}

\section{Dayane Julia Carvalho Dias}

Universidade Estadual de Campinas

\section{Resumo}

O trabalho pretende analisar alguns dados demográficos sobre a capitania do Rio Grande, na região norte do Estado do Brasil, com base em registros de batismos da Freguesia de Nossa Senhora de Apresentação, contemplando os aldeamentos e algumas capelas rurais, entre os anos de 1681 e 1714, período cujo contexto era conturbado em decorrência da chamada Guerra dos Bárbaros. Os dados mostram algumas características interessantes sobre o perfil daquela população à época. A análise, ancorada na totalidade de batizandos, incluindo livres e escravos, procurará privilegiar os escravos, segmento significativo da sociedade colonial da capitania do Rio Grande. Assim, procurou-se analisar, com base nos registros paroquiais de batismos, os seguintes elementos: distribuição geográfica dos locais de batismos (população total, escravizados negros e indígenas); condição jurídica; distribuição por sexo; razão entre sexos; quantidade de batismos por anos de escravos negros e indígenas; locais de procedência dos escravos de origem africana; e por fim, relações familiares dos escravos negros, no que se refere à categoria de idade (dividido entre crianças, adultos e informações ausentes), e no caso das crianças, o estado civil de suas mães.

Palavras-chaves: Capitania do Rio Grande; População Escrava; População Indígena; Batismos; Guerra dos Bárbaros.

\author{
Carmen Margarida Oliveira Alveal \\ Universidade Federal do Rio Grande do Norte
}

\section{Abstract}

This article intends to analyze some demographic data about the captaincy of Rio Grande, in the northern region of the State of Brazil, based on records of baptisms of the Parish of Nossa Senhora de Apresentação, including villages, Indian settlements and some rural chapels, from 1681 to 1714 , period whose context was complicated because of the so-called Barbarian War (Indians). The data show some interesting characteristics about the profile of this population at that time. The analysis, anchored in the totality of baptisms, including free and enslaves people, will seek to privilege slaves, a significant segment of the colonial society of the Rio Grande captaincy. Based on the parish records of baptisms, we sought to analyze the following elements: geographical distribution of baptismal sites (total population, black and Indian enslaved); legal status; distribution by sex; sex ratio; number of baptisms per year of slaves; places of origin of slaves from Africa; and finally, family relations of slaves of African origin, as regards the age category (divided among children, adults and missing information), and in the case of children, the marital status of their mothers.

Keywords: Captaincy of Rio Grande; Slave Population; Indian Population; Baptisms; Barbarian War. 


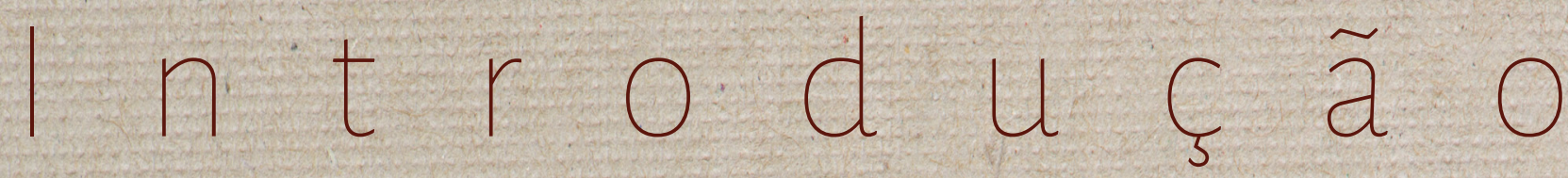

A colonização do Rio Grande foi retomada após a expulsão dos holandeses, em 1654, e foi caracterizada, em seu início, por uma economia incipiente, assim como pelas disputas violentas por terras entre indígenas, colonos e missionários, período conhecido como a Guerra dos Bárbaros (PIRES, 1990; PUNTONI, 2000; LOPES, 2003; ALVEAL, 2013 e 2016). Este artigo pretende analisar o contexto histórico e demográfico no qual estava inserida a sociedade colonial do Rio Grande, com base em registros paroquiais de batismos do período de 1681 a 1714. Pretende-se realizar uma discussão principalmente sobre a população escravizada, tanto indígena quanto negra, propondo-se a analisar essas populações que constituíram famílias com suas especificidades, mesmo em um contexto difícil e de princípio da construção da sociedade colonial na capitania.

O objetivo desse artigo, portanto, é apresentar características sociodemográficas da população negra e indígena escravizada, e também da população livre na Freguesia de Nossa Senhora da Apresentação, que englobava praticamente toda a capitania daquele período, incluindo a matriz, na cidade do Natal, os aldeamentos indígenas de Cuaraíras e Guajirú, e algumas capelas rurais (São José de Mipibu, Nossa Senhora do Desterro, Nossa Senhora dos Prazeres de Coianinha, Capela de Cunhaú, Oratório de Jundiaí, Capela de São Conçalo do Potengi e Capela de Santo Antônio do Potengi). Renata Assunção da Costa (2015), em sua dissertação de mestrado, utilizando-se de mesmo material, mapeou a localização de todas essas igrejas, capelas e oratório, evidenciando como, geograficamente, a população da época estava basicamente contida no litoral, no entorno da cidade do $\mathrm{Natal}$, capital da capitania, não muito mais do que 40 a 50 quilômetros de distância dessa localidade. Além dessas regiões, havia no litoral sul, também não distando mais de 30 quilômetros da costa, o engenho Cunhaú, área que concentrava significativa quantidade populacional.

Os aspectos analisados a partir dos registros paroquiais de batismos foram: distribuição geográfica dos locais de batismos (população total, escravos negros e indígenas); condição jurídi-

1 Utilizar-se-á Rio Grande, sem. "do norte", uma vez que o termo apareceu somente em 1751, para diferenciar a região da capitania do São Pedro do Rio Grande do Sul, e o período aqui estudado é anterior. 
ca; distribuição por sexo; razão entre os sexos; quantidade de batismos por anos de escravos indígenas e negros; locais de procedência dos escravos negros, se nascidos no Brasil ou na África; e por fim, relações familiares dos escravizados negros, no que se refere à categoria de idade (dividido entre crianças, adultos e informações ausentes), e no caso das crianças, o estado civil de suas mães.

No período colonial, a lgreja constituía-se em uma peça fundamental na sociedade, cujos procedimentos de casamentos, batismos e óbitos tornavam-se obrigatórios para quem fizesse parte da esfera política, administrativa e social do Império Português, como forma de se enquadrar no modelo social imposto. Foi com o desenvolvimento da demografia histórica a partir de 1950 , e com a utilização dos registros de casamentos, óbitos e batizados, que o estudo das famílias e outras áreas se consolidaram, incluindo os estudos da família escrava no Brasil (FARIA, 1997).

Há décadas, diferentes autores têm dedicado-se às análises voltadas para a participação dos negros e indígenas na formação da sociedade brasileira. Quanto aos primeiros, destacam-se, nos trabalhos desenvolvidos nas últimas décadas, abordagens historiográficas que pretendem romper com a ideia de "coisificação" do negro, e compreendem essa camada da sociedade colonial por um viés diferenciado, ou seja, como agentes sociais, como é o caso de Stuart Schwartz (1988), Robert Slenes (1999) e Sheila de Castro Faria (1998), que focaram em pesquisas que permitissem perceber a participação dos negros enquanto sujeitos históricos, constituidores de famílias. Outros estudos têm focado nas diferentes etnias, mostrando a complexidade das relações dos escravos de origem africana e seu estabelecimento no Brasil, bem como suas estratégias de sobrevivência e ascensão a partir dos registros de batismos e das relações de compadrio (SOARES, 2000 e 2010; KÜHN, 2015).

Nesta perspectiva, serão apresentados os resultados dessa pesquisa para o Rio Grande, capitania cujo estudo sobre a escravidão tem sido prejudicado por duas razões: por um lado, a dificuldade de fontes, e por outro, o discurso dos estudos clássicos produzidos na primeira metade do século $\mathrm{XX}$, ao afirmar que, pelo fato de a região não ter tido economia exportadora, não teria feito uso de escravos de forma maciça, não sendo necessários estudos mais elaborados por parte dos historiadores (ROCHA POMBO, 1922; LYRA, 1998 [1922]; CASCUDO, 1955). Discordando dessa visão, este trabalho procurar mostrar que a capitania do Rio Grande, mesmo não tendo prioritariamente lavouras de grande extensão voltadas para a exportação, estava inserida em um contexto escravista, no qual, quando possível, para os conquistadores foi importante ter escravos, no sentido de se diferenciarem socialmente, uma vez que, na colônia, ser senhor de terras e escravos os distinguia na hierarquia social. As fontes analisadas foram os registros de batismos da freguesia de Nossa Senhora da Apresentação, contemplando os aldeamentos e 
algumas capelas rurais do período de 1681 a 1714. Raros são os registros anteriores ao século XVIII. Entretanto, foram encontrados, no Instituto Arqueológico, Histórico e Geográfico Pernambucano (IAHCP), em Recife, duas partes do que uma vez deve ter composto um ou mais livros de registros de batismos da então capitania do Rio Grande. Infelizmente não foram en-' contrados registros de matrimônios e óbitos para o mesmo período. Mas esta documentação já possibilita a construção de indicadores demográficos, levando-se em consideração o contexto histórico da população a ser estudada. Para tratamento das informações, utilizou-se o software NACAOB, que tem permitido o desenvolvimento de estudos na área de Demografia Histórica, História da Família e História da População. A forma de funcionamento do software consiste na coleta e organização, por meio da inserção das informações referentes aos batismos, casamentos e óbitos - no caso deste artigo organizou-se as informações de batismos. O NACAOB permite que o pesquisador extraia tabelas contendo os nomes e principais informações de todos os indivíduos inseridos no banco de dados (SCOTT \& SCOTT, 2006 e 2013).

\section{O período da chamada Guerra dos Bárbaros e o povoamento do Rio Grande}

A Cuerra dos Bárbaros faz referência ao período em que houve um incremento no avanço dos sertões no interior das capitanias da Paraíba, Rio Grande e Ceará, havendo choques entre os desbravadores e os indígenas que habitavam a região. Essa ampliação no processo de colonização portuguesa nessa área ocorreu após a expulsão definitiva dos holandeses, em 1654. A partir dessa data, primeiramente o próprio litoral foi reorganizado, tendo as poucas instituições sido reintroduzidas, como as Câmaras e as tropas de ordenanças.

O tema da Cuerra dos Bárbaros foi importante para a história local, dado que Vicente Lemos (1912), ao investigar a atuação dos capitães-mores da capitania do Rio Grande, já destacou a importância desses agentes no enfrentando dos índios no interior. Seus estudos contribuíram para as análises das sínteses feitas em comemoração ao centenário da independência, escritas por Rocha Pombo (1922) e Tavares de Lyra 1998[1922]) e mais tarde o estudo de Luís da Câmara Cascudo (1955). Afonso d'Escragnolle Taunnay (1930), perseguindo o objetivo de valorizar a, atuação dos paulistas na fundação da nação, também analisou a guerra dos bárbaros. Todas essas são perspectivas consideradas clássicas, nas quais se percebia a resistência indígena, em especial dos tapuias, como entrave à colonização.

Somente no final do século XX novas perspectivas surgiram, sendo o primeiro estudo de Maria Idalina da Cruz Pires (1990), no qual tentou investigar os diferentes interesses dos grupos envolvidos ná guerra. Já Pedro Puntoni (2000), em estudo de maior fôlego, abordou a Cuerra dos Bárba- 
ros desde os primeiros entraves na Bahia, em meados do século XVII, até a Guerra do Açú, no Rio Grande, em fins do XVII perpassando ao início do XVIII, percebendo os embates entre os locais e as tropas de paulistas e seus diferentes ganhos.

Ao se reiniciar o processo de colonização, após a expulsão dos holandeses, no caso do Rio Grande, a Câmara foi restabelecida e o capitão-mor da capitania retomou a distribuição de sesmarias na capitania, títulos de propriedade da terra do período colonial. Nas primeiras décadas, aproximadamente entre 1660 e 1670, foi priorizado o litoral (ALVEAL, 2013). Uma vez que os terrenos da faixa litorânea não eram tão propícios para a lavoura da cana-de-açúcar como os litorais das capitanias de Pernambuco e Paraíba, os moradores da capitania do Rio Grande acabaram por se especializar na lavoura de mandioca e na consequente produção de farinha, assim como na criação do gado.

Apesar de a produção de farinha e outros gêneros para autoconsumo e a criação de gado terem sido as principais atividades econômicas da região, isso não significa a inexistência de lavouras de cana-de-açúcar. Houve um grande engenho, de Cunhaú, ao sul da capitania, que sempre teve participação relevante na produção do açúcar que era levado para o porto de Recife. Ademais, havia pequenas engenhocas que produziam rapadura e aguardente para o consumo local.

A criação de gado, no entanto, tornou-se uma atividade que contribuiu para o avanço na ocupação das terras para além do litoral (DIAS, 2015). Cada vez mais vinham moradores de outras capitanias solicitando sesmarias com vistas à pecuária, inclusive famílias da açucarocracia de Olinda², que procuravam diversificar seus negócios devido à crise do açúcar que passou a afetar esse grupo ${ }^{3}$. A partir de 1680, apesar de ter havido já um processo de aldeamento de grupos indígenas no litoral, como as aldeias de Guajiru e Cuaraíras ${ }^{4}$, havendo uma tentativa, principalmente por parte de missionários, de inserir esses grupos na sociedade colonial, vários outros grupos de índios, conhecidos pela categoria genérica de tapuias ${ }^{5}$, não ficaram contentes com tal avanço.

Assim, muitos ataques realizados pelos tapuias ao gado ou às próprias moradias desses desbravadores ocorreram, levando muitos a retornarem para o litoral. O governo local, tanto a Câmara da cidade do Natal, quanto o capitão-mor, responsável pela defesa da capitania, passou a pedir ajuda ao gover-

2 Tais famílias possuíam engenhos em várias localidades, mas controlavam o poder político de Olinda, principal Câmara das Capitanias do Norte. Com o incêndio de Olinda, ocasionado pelos holandeses, e a consequente degradação da Vila, vários senhores preferiram habitar em seus engenhos, mas continuaram controlando o poder na Câmara na segunda metade do século XVII, tentando fazer frente ao crescimento do poder dos comerciantes de Recife, que ainda não era vila, fato que ocorreria somente em 1711, após grandes embates como a Cuerra dos Mascates (MELLO, 2003; 2007; 2008).

3 Estudo recente de Morais (2014) aborda a família Carneiro da Cunha, tradicional família açucareira de Pernambuco, que passou a pedir sesmarias e comprar terras nas capitanias do Ceará e do Rio Grande, e a participar da atividade da pecuária. 4 Os aldeamentos, realizados principalmente por missionários religiosos, foram importante instrumento da Coroa no sentido de permitir aos índios uma possibilidade de um mal menor do que a escravização (ALMEIDA, 2013). Para um estudo dos aldeamentos dos índios no Rio Grande, ver Lopes (2003).

5 Tapuia era o termo utilizado pelos índios Tupi, habitantes do litoral, para se referir às populações que habitavam as áreas longe do litoral. Constituíam-se de vários grupos étnicos. Os portugueses se apropriaram do termo para se referir aos índios do interior (LOPES, 2003). 
no geral, em Salvador. O próprio governo de Pernambuco e a Câmara de Olinda também acudiram os pedidos de socorro, levando a um embate entre o governador-geral, de um lado, e o governador de Pernambuco e capitão-mor do Rio Grande, de outro (ALVEAL SILVA, 2012).

O governador geral na Bahia decidiu enviar uma tropa, conhecida como Terço dos Paulistas, composta tanto por paulistas bem como por outras pessoas de diversas origens, inclusive mestiços e índios. Essa tropa chegou ao Rio Grande no ano de 1695 e, agindo de forma enérgica, travou confrontos violentos contra populações indígenas. O final da Guerra dos Bárbaros, nome que ficou consolidado na historiografia pela referência dos portugueses a esses grupos, aconteceu por volta do ano de 1720 (PUNTONI, 2000; SILVA, 2015).

É nesse período conturbado de colonização do interior, entre 1680 e 1720, e da consolidação de algumas atividades econômicas, como a pecuária, a pescaria, a salineira e a pequena produção agrícola, com o uso da mão-de-obra escrava tanto de indígena quanto negra, que os dados demográficos serão analisados, a partir das seguintes hipóteses de trabalho: a) apesar de o Rio Grande não ter tido uma atividade econômica vinculada à exportação, não deixou de utilizar mão de obra escrava em outras atividades; b) embora o elemento indígena tenha sido utilizado comó mão de obra escrava, muito em decorrência da própria Cuerra dos Bárbaros, vários foram os escravos negros utilizados também como mão de obra, evidenciando que, mesmo não fazendo parte dos grandes lucros da economia açucareira, as famílias tinham cabedal para possuir escravos negros, considerados mais caros que os indígenas, inclusive alguns vindo diretamente da África, ou seja, negros não nascidos na América portuguesa; c) não houve o massacre ou a completa dizimação dos índios tão apontada pela chamada historiografia clássica, quanto por alguns estudos recentes, que salientam a violência da ação dos Paulistas na Guerra dos Bárbaros ${ }^{6}$.

Em segundo lugar, os dados mostrarão que, apesar do estado conturbado de guerra, os moradores puderam: a) realizar o sacramento do batismo, tão importante no período colonial; b) indígenas e negros podiam se casar em frente à Igreja Católica, bem como batizar seus filhos.

\section{Indicadores demográficos}

O conjunto de registros é composto por duas partes, não sendo certo se pertenciam a um mesmo livro ou a livros diferentes. É sabido que tal conjunto comporta registros de batismos da antiga

60 grupo conhecido como os clássicos historiadores que escreveram sobre a história do Rio Grande do Norte é composto por Cascudo (1955), Lyra (2008 [1922]) e Pombo (1922). Além destes, o estudo de Puntoni (2000) corrobora para a ideia de extermínio completo dos indígenas. Assim, essa historiografia sinalizou para uma suposta extinção dos indígenas na capitania do Rio Grande. Estudos mais recentes como os de Macedo (2011) já demonstram que essa extinção não existiu. 
Freguesia de Nossa Senhora da Apresentação, da cidade de Natal7 ${ }^{7}$, na capitania do Rio Grande. Os registros totalizam 957 batismos entre os anos de 1688 e 1714. Deve-se levar em consideração que uma fração não estava inclusa nessa "sociedade colonial" ainda em formação, sobretudo os índios tapuias, em que constam apenas os que foram aldeados, escravizados e batizados.

Analisando-se de forma mais a profundada quem eram esses batizandos, será observada a distribuição espacial dos batismos. O Gráfico 1 refere-se à distribuição do local do batismo da população total. É importante ressaltar que não foram contabilizados dois registros, o realizado em Camaratuba (PB), e um feito em casa. Houve casos de três escravos serem batizados no mesmo registro. Também ocorreram casos de gêmeos. Portanto, foram computados 944 registros com local de batismo, de um total de 957.

Dos 957 batismos analisados, em 944 constavám informações de local de batismos e, destes, a maioria foi realizada na Matriz de Nossa Senhora da Apresentação em Natal, totalizando 288 batismos, ou cerca de 31\%. Em segundo lugar, há os batismos realizados na Capela de Santo Antônio, atual São Gonçalo do Amarante (total de 176 registros, correspondendo a 19\%). Em terceiro lugar, destaca-se a aldeia de Mipibú, atual São José de Mipibú (138 registros, ou cerca de $15 \%$ ), seguido pela Capela de São Conçalo do Potengi (72 registros, ou $8 \%$ ) e a aldeia de Guajirú, atual Extremoz (70 registros, cerca de $7,5 \%)^{8}$. Destaca-se que o número de registros que não constavam o local de batismo ou estava ilegível é de 99 , correspondendo a 10,5\%.

Gráfico 1 - Local de batismo, população total da Capitania do Rio Grande, 1681-1714.

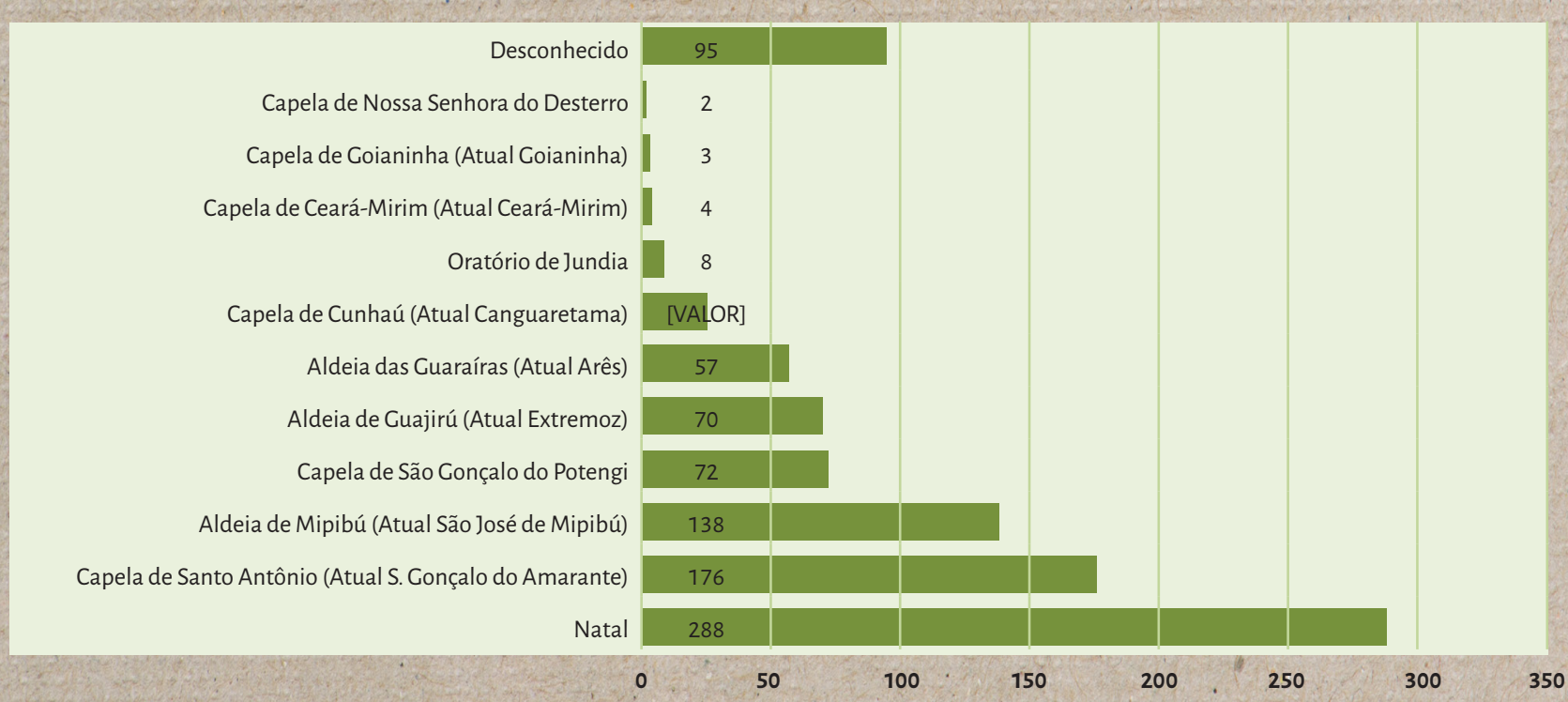

Fonte: Elaborado pelas autoras a partir de dados dos registros paroquiais de batismos da Freguesia de Natal, Rio Grande do Norte (IAHCP, 1681-1714).

7 Esta foi a única freguesia da capitania até o ano de 1726, com a fundação da freguesia do Assú, um dos palcos da Guerra dos Bárbaros, consolidando o avanço dos conquistadores no sertão com a criação dessa freguesia bem ao interior.

8 Luís da Câmara Cascudo (1968), em seu livro Nomes da Terra, apresenta a correspondência dos nomes atuais, bem como o significádo dos nomes das várias localidades. 
A distribuição dos batismos realizados na Capitania do Rio Grande neste período representa um pouco da localização geográfica onde esses batismos eram realizados. Percebe-se que Natal, por ser o núcleo de povoamento mais antigo, ser a capital da capitania e abrigar grande parte da população, possui grande número de batismos realizados. Mas os aldeamentos indígenas também se destacaram, evidenciando sua grande importância neste período inicial de formação da sociedade. Apesar de nem todos os batizandos nessas aldeias serem indígenas, a sociedade colonial da capitania do Rio Grande construiu-se em torno dessas aldeias?. O Gráfico 2 expressa como a sociedade estava dividida por condição jurídica entre pessoas livres e escravos.

Gráfico 2 - Condiçãojurídica da população na Capitania do Rio Grande, 1687-1714.
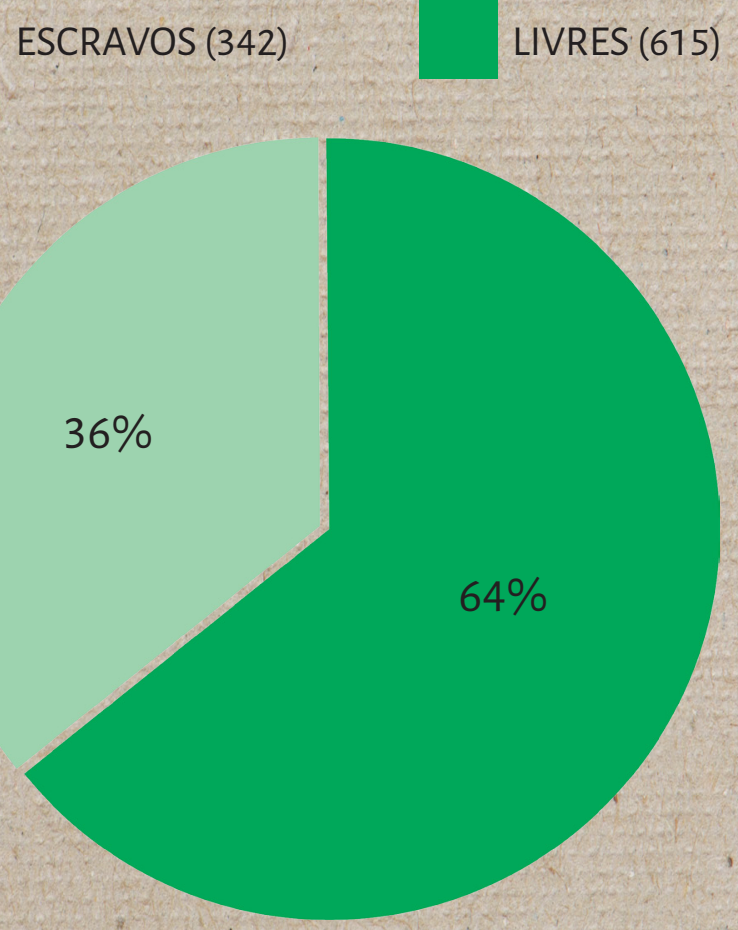

Fonte: Elaborado pelas autoras a partir de dados dos registros paroquiais de batismos da Freguesia de Natal, Rio Grande do Norte (IAHCP, 1681-1714).

Para a produção do Gráfico 2, foram considerados 957 registros de batismos. Desse total, $64 \%$ ou 615 pessoas eram livres, e $36 \%$ escravos, tanto negros quanto indígenas, correspondendo a 342 batizandos. Conforme os resultados, pode-se ressaltar alguns aspectos da sociedade colonial ainda em formação no Rio Grande. O principal é que a maioria da população era composta de pessoas consideradas livres, corroborando o fato de que a escravidão foi menor do que em outras áreas. Portanto, havia uma economia que não motivava a busca incessante por escravos, culminando em números superiores da população livre em relação à escrava.

9 Costa (2015) mostra, em sua dissertação, como nos registros de alguns aldeamentos destacava-se muito mais o batismo de não indígenas do que o de indígenas. 
A economia da capitania do Rio Grande não comportava atividades voltadas para a grande lavoura exportadora, portanto, não utilizou muito a mão de obra escrava. Mas, ainda assim, os escravos estavam presentes no processo de construção da sociedade colonial local, sendo $36 \%$ de batizandos, correspondendo ao número de 342 de crianças ou adultos que estavam na con-' dição de escravos quando foram submetidos ao sacramento do batismo -bem mais de $1 / 4$ da população submetida aos padrões eclesiásticos.

Durante muito tempo, na historiografia do Rio Grande do Norte (ROCHA POMBO, 1922; LYRA, 2008 [1922], CASCUDO, 1955), acreditou-se que os escravos negros e índios eram tão poucos que não se constituiriam em uma parcela significativa a ser considerada. No entanto, como se verifica nos Gráficos 1 e 2 , a parcela de $36 \%$ de escravos na população é significativa. Mesmo que não cheguem à metade da população batizada, não é possível ignorar esse segmento da participação da sociedade. Os dados indicam que os escravos estavam se inserindo nessa sociedade em formação, participando, inclusive dos rituais de sacramentos da Igreja Católica à época. Ademais, se $36 \%$ da população batizada era escrava, mesmo que não tenha sido a base da mão de obra, ensejando outras relações de trabalho, ainda assim é um número considerável e, portanto, pode-se falar que a sociedade da capitania do Rio Crande era escravista e agia de modo semelhante às outras regiões em que a escravidão era mais preponderante.

Conhecido como a sociedade colonial estava dividida por meio da condição jurídica, torna-se importante conhecer também o sexo e a razão de sexo dos indivíduos batizados, conforme pode ser verificado na Tabela 1. A divisão foi feita por categorias de livres (615), os escravos negros (271) e os escravos indígenas (71), que juntos totalizam 957 batismos.

Tabela 1 - Sexo e Razão de Sexo na Capitania do Rio Grande, 1681-1714.

\begin{tabular}{|c|c|c|c|c|c|}
\hline \multirow{2}{*}{ Categoria } & \multicolumn{4}{|c|}{ Sexo } & \multirow{2}{*}{ Razão de Sexo } \\
\hline & Masculino & $\%$ & Feminino & $\%$ & \\
\hline Livres & 314 & 51 & 301 & 49 & 104,3 \\
\hline Escravos negros & 143 & 53 & 128 & 47 & 111,7 \\
\hline Escravos indígenas & 32 & 45 & 39 & 55 & 82,1 \\
\hline
\end{tabular}

Fonte: Elaborado pelas autoras a partir de dados dos registros paroquiais de batismos da Freguesia de Natal, Rio Grande do Norte (IAHGP, 1681-1714).

A razão de sexo expressa a relação quantitativa entre os sexos. Quando à razão de sexo é igual a 100, o número de homens e mulheres se equivale, estando em equilíbrio "perfeito". Se está abaixo de 100, há predominância de mulheres na população e, acima de 100, predominância de homens, mostrando certo desequilíbrio, isto é, quanto maior a discrepância entre eles, maior o deséquilíbrio entre os sexos, podendo acarretar consequências demográficas. O indicador é 
influenciado por taxas de migração e de mortalidade diferenciadas por sexo e idade (SHRYOCK \& SIECEL, 1976; CERQUEIRA \& GIVISIEZ, 2004).

Para a população de pessoas livres, a razão de sexo demonstrou um quase equilíbrio de 104,3, com um leve predomínio de homens na população. De acordo com o Gráfico 6, mostrado mais adiante, a maioria dos indivíduos batizados era de crianças, e a diferença entre os sexos nessa idade não era tão grande, visto que nasciam tanto homens como mulheres de forma quase igual. Ceralmente, em populações em que há predominância do sexo feminino, houve sobremortalidade masculina, sobretudo nas idades jovens e adultas, decorrentes da alta incidência de óbitos por causas violentas. Tal como pode ser o caso da razão de sexo da população escrava indígena, que apresentou uma razão de sexo de 82,1, indicando uma predominância de muTheres escravas na população. Um dos motivos para esse desequilíbrio seria a participação da população indígena na Guerra dos Bárbaros, o que teria reduzido o número de índios do sexo masculino, que entraram em combate direto com os colonizadores.

Essa diferença entre os sexos corrobora a questão de os homens indígenas terem sido o maior número de vítimas da Guerra dos Bárbaros. As mulheres e crianças que sobreviveram aos combates tornaram-se escravas; já os homens adultos acabaram perecendo, lutando até o fim contra o destino que, muito provavelmente, seria o das indígenas escravizadas, ou mesmo mortos deliberadamente para não possibilitar a fecundidade entre esses grupos étnicos (TORRES-LONDOÑO,1999). Outro aspecto a ser destacado é que os escravos indígenas foram provenientes desses embates e, provavelmente, foram aprisionados e vendidos localmente a preços inferiores do que os negros escravizados. Ou mesmo aqueles, os chamados conquistadores, que lutaram contra os indígenas, acabaram por retê-los como seus prisioneiros, transformando-os em escravos como espólio de guerra (MONTEIRO, 1994; LOPES, 2003; OLIVEIRA, 2004; Hemming, 2007).

Em relação à razão de sexo de 111,7 de escravos negros, a predominância de homens na população poderia ser explicada pela preferência do sexo masculino para mão de obra econômica, apesar de a capitania do Rio Grande não ter sido cenário de grandes lavouras dedicadas a produtos de exportação, tendo se especializado mais na pecuária e na lavoura para autoconsumo, como a mandioca e a produção de farinha.

Para aprofundar a análise da questão da escravidão, também foram elaborados gráficos de local de batismos. O Gráfico 3 refere-se aos locais predominantes de batismos da população escrava negra. Dos 261 registros de batismos, encontram-se os seguintes dados: 
Gráfico 3 - Local de batismo, população negra escrava na Capitania do Rio Grande, 1687-1714.

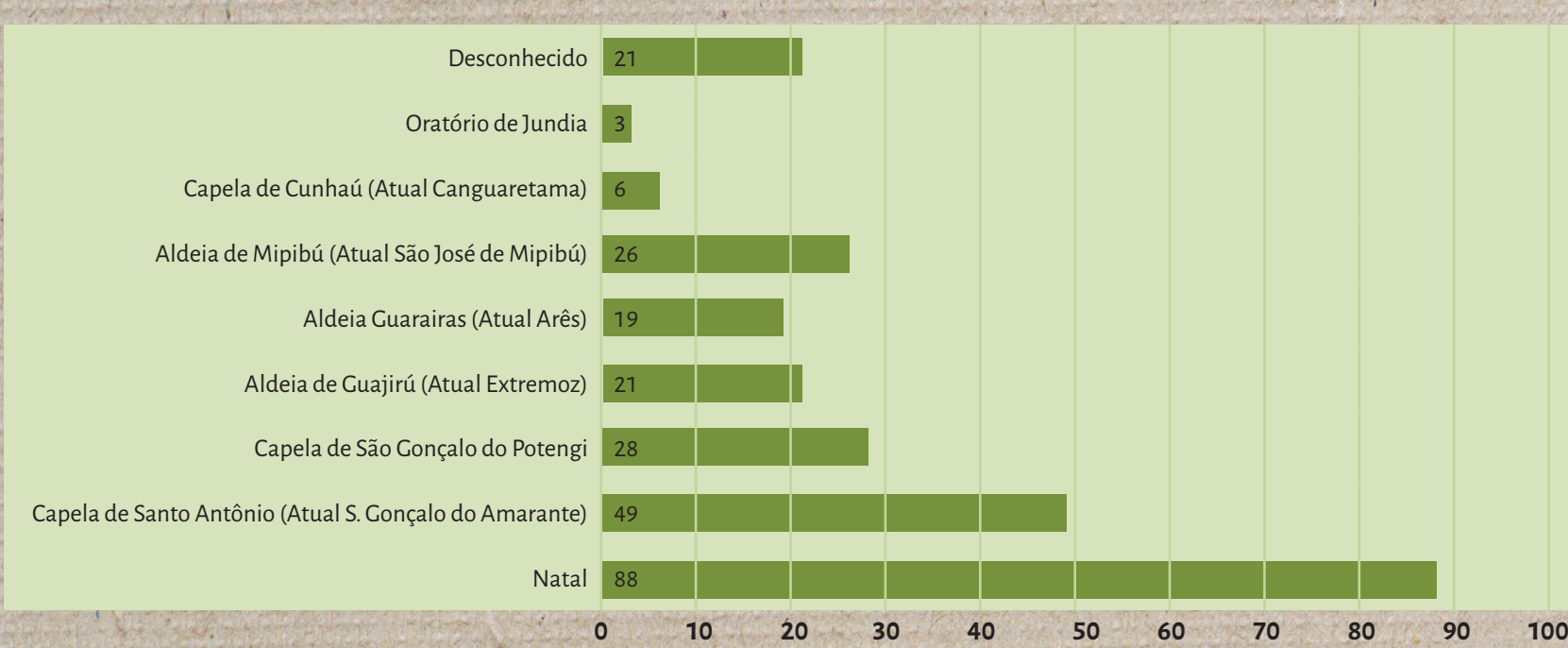

Fonte: Elaborado pelas autoras a partir de dados dos registros paroquiais de batismos da Freguesia de Natal, Rio Grande do Norte (IAHCP, 1681-1714).

De acordo com os registros, a maioria dos batismos de população negra escrava ocorreu em Natal (88), seguido pela Capela de Santo Antônio do Potengi (49) e pela Capela de São Conçalo do Potengi (28). Esses resultados podem indicar que as atividades que envolviam a mão de obra escrava giravam em torno desses locais, pelo menos, foi o que pôde ser filtrado pelos registros paroquiais. Apesar de também não ser uma cidade com alto grau de dinamicidade, parece ter exercido certa centralidade das ações da lgreja ou, talvez, diante das dificuldades da ida de clérigos aos locais mais remotos, é possível que houvesse um esforço de se ir até a capital para garantir o sacramento (COSTA, 2015).

O batismo de escravos no período colonial era um meio de enquadrar essas pessoas, por meio da religião, no modelo social existente, especialmente através da adoção de um nơme cristão, embora no sentido econômico e social mantivessem-se as diferenças. Os escravos vindos diretamente da África tinham os seus nomes mudados durante o batismo instituído pela Igreja Católica, fator de integração simbólica do gentio escravizado (SOARES, 2010, p. 81). Alguns nomes eram mudados já nos portos da África.

Conforme as Ordenações Filipinas, o proprietário era obrigado a realizar o batismo do gentio logo após a compra, tendo prazo de seis meses para cumprir essa obrigação. Em càso de denúncia do não cumprimento, poderia haver a perda da propriedade. Até 1707,0 escravo era considerado adulto com 10 anos, mas com as Constituições primeiras do Arcebispado da Bahia, de 1707, passou a sete anos. O escravo, considerado adulto, deveria ser levado ao vigário da freguesia, para ser batizado dentre os seis meses (CONSTITUIÇÕES DO ARCEBISPADO DA BAHIA, 1853 [1707]; SOARES, 2017). 
Com relação aos indígenas, esses poderiam ser aprisionados somente por meio da guerra justa, justificativa que foi utilizada no momento da Guerra dos Bárbaros (PERRONE-MOISÉS, 1992). Apesar de a guerra ser mais entendida como uma reação dos índios à entrada cada vez mais ao interior dos conquistadores, para esses o entendimento era de que eles estavam sendo atacados, justificando a matança ou aprisionamento dos grupos tapuias que viviam nos sertões da capitania (PIRES, 1990).

Gráfico 4-Local de batismo, população escrava indígena na Capitania do Rio Grande, 1681-1714

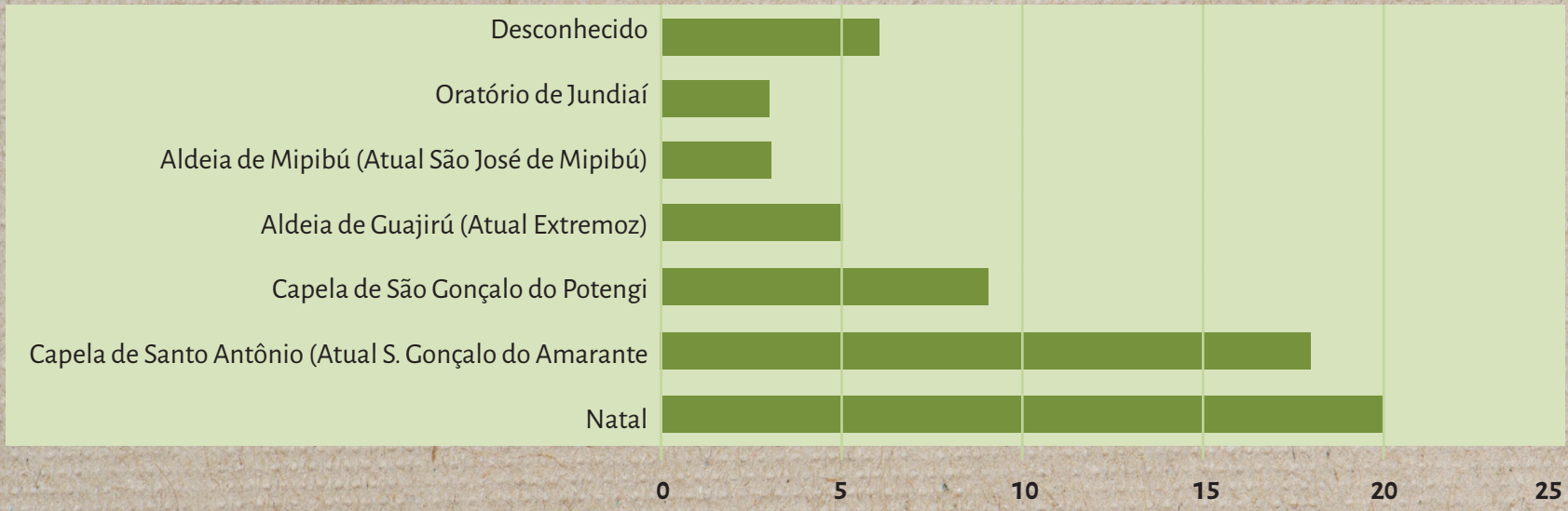

Fonte: Elaborado pelas autoras a partir de dados dos registros paroquiais de batismos da Freguesia de Natal, Rio Grande do Norte (IAHGP, 1681-1714).

À medida que os conquistadores avançavam em terras nas quais os Janduís, Icós, Cariri, Canindé, Paiacú, Panatis, Tarariús, entre outros, denominados genericamente de tapuias, tinham suas áreas de deslocamento, os confrontos aumentavam, uma vez que se viam ameaçados (LOPES, 2003). O Gráfico 4 diz respeito aos locais de batismos da população escrava indígena.

Os batismos da população escrava indígena ocorreram prédominantemente na Igreja Matriz de Nossa Senhora da Apresentação em Natal (20), seguido pela Capela de Santo Antônio (18) e pela Capela de São Conçalo do Potengi (9). São poucos os registros de batismos de população escravizada indígena. Na história colonial do Brasil e também do Rio Grande, percebe-se que os indígenas também foram escravizados no início da colonização, mas a preferência recaiu, conforme o tempo, sobre a população negra.

O levantamento do número de batismos por ano permite analisar a sazonalidade de ocorrência do registro dos eventos vitais na Capitania do Rio Grande, conforme pode ser verificado no Cráfico 5 para a população de escravos negros e indígenas. 
Gráfico 5-Batismos por ano dos registros de escravos na Capitania do Rio Grande, 1681-1714.

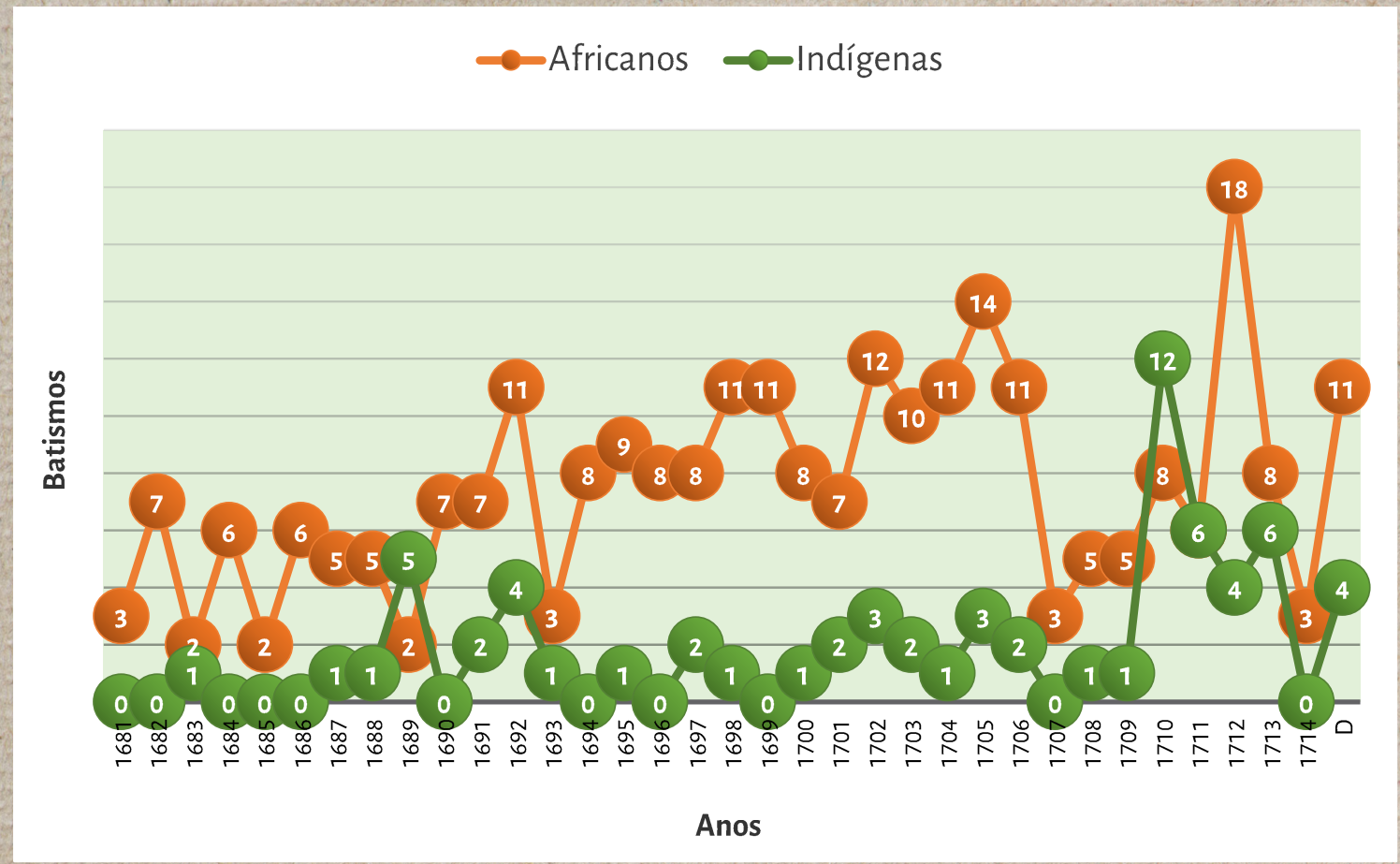

Legenda: $\mathrm{D}=$ desconhecido.

Fonte: Elaborado pelas autoras a partir de dados dos registros paroquiais de batismos da Freguesia de Natal, Rio Grande do Norte (IAHCP, 1681-1714).

O número de batismos da população escrava negra variou ao longo dos anos considerados. Da década de 1680 para a de 1690 , a média de batismos por ano quase dobra, e a partir desse momento apresentou uma média de 10 a 14 em 1692, 1698, 1699, e entre 1702 e 1706. Apesar de algumas variações, pode-se perceber o ano de 1692 como data indicativa de uma consolidação do avanço sobre o interior da capitania, aumentando a potencialidade econômica da região, com o aumento do uso da mão de obra escrava. O ponto mais alto foi de 18 batismos em 1712 , um período que já indica o domínio dos conquistadores no interior e de maior dinâmica na economia, o que permitiu a compra desses escravos. Os anos de 1706 a 1711, com números mais baixos, podem indicar anos de instabilidade econômica, e ressalta-se que. ainda nesse período. ocorriam os embates com os tapuias. O número total de batismos de escravos negros que constava informação do ano foi de 261 de um total de 271 registros. Cabe observar que o número de registros anuais é bastante baixo, caso se compare com outras regiões, como, por exemplo, a Bahia (SILVA JÚNIOR, 2016), mas é tão baixo quanto de outra região considerada periférica, como a Colônia do Sacramento nas décadas de 1730 e 1740 (KÜHN, 2015).

Já o número de batismos por ano de escravos indígenas foi mais baixo ainda: pouco variou entre 1 e 6 , e chegou a 12 batismos em 1710, provavelmente resultado de embates no sertão do 
Açu. O total geral foi de 67 registros em que constavam informações de anos, de um total de 71 registros. Percebe-se que nem em todos os registros constavam o ano do batismo. Claramente, esses dados estão sujeitos a problemas de enumeração, sobretudo, os erros de subenumeração, quando os levantamentos dos dados estão distantes do que foi a realidade, deixaram de ser registrados por diversos motivos ou foram registrados de forma errada. No entanto, apesar dos problemas, a existência rara desses dados permite pensar um pouco sobre alguns aspectos demográficos da época.

Passando-se a analisar somente os escravos que foram declarados enquanto provenientes da África, pode-se perceber, no Gráfico 6, o local de procedência desses escravos. Antes de passar-se aos números, é importante alertar que as denominações étnicas registradas nos batismos não necessariamente podem corresponder aos locais de fato da origem do escravo na África. Entretanto, como se discutirá adiante, em diálogo com a bibliografia especializada sobre o tráfico atlântico, acredita-se que as nomenclaturas utilizadas nos registros paroquiais analisados estejam de certa maneira corretos. No caso do Rio Grande, para o período entre 1681 e 1714 foram encontrados os seguintes dados:

Gráfico 6-Local de procedência dos escravos de origem a fricana na Capitania do Rio Grande, 1681-1714.

Centio de Arda (6) Gentio de Guiné (19)

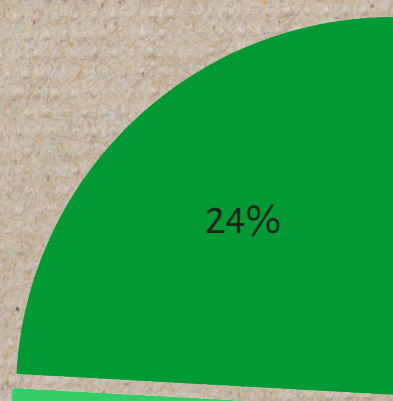

$76 \%$

Fonte: Elaborado pelas autoras a partir de dados dos registros paroquiais de batismos da Freguesia de Natal, Rio Grande do Norte (IAHCP, 1681-1714). 
Dos 271 registros de escravos negros analisados, somente em 25 constam informações de locais de procedência do continente africano. Provavelmente, o restante de 246 registros era de escravos já nascidos no Brasil, mostrando um presumível crescimento endógeno, embora não se possa afirmar que isso ocorria na própria capitania do Rio Grande, ou era decorrente do aumento da oferta, no último quartel do século XVII, de escravos de Pernambuco e da Paraíba, ou mesmo da Bahia, que eram revendidos no Rio Grande. Lamentavelmente, a compreensão do funcionamento da rota do comércio de escravos entre os principais portos na América portuguesa e as regiões periféricas, como o Rio Grande, ainda é inexistente, e por essa razão foram utilizados trabalhos que mais se aproximam, geograficamente, da explicação das rotas do tráfico em relação ao espaço de estudo, como é o caso de Recife.

Desses 25 registros, $76 \%$ eram provenientes do gentio de Guiné, e $24 \%$ do gentio de Arda. Primeira constatação a ser feita é como esses escravos chegavam ao Rio Grande ainda sem ser batizados, nem no porto de embarque no continente africano, nem no porto de chegada. Uma pergunta que no momento não pode ser respondida é: será que os proprietários do Rio Grande iam diretamente a Recife comprar os escravos, ou comerciantes de Pernambuco os levavam até Natal? Por trás dessa pergunta se coloca o questionamento se não havia o receio de o batismo não ser realizado no período que a legislação ordenava, pois corria-se o risco de perda da mercadoria, o que não era interessante nem para o comerciante nem para o senhor de escravos.

Informação que interessa ao leitor é sobre a explicação de que escravos provenientes da Costa da Mina, justamente a região de onde vinham os escravos batizados do Rio Grande. Segundo Fábio Kühn (2015, p. 5), "estes escravos vindos da África Ocidental eram embarcados ainda 'pagãos', ao passo que os provenientes da região congo-angolana viriam já batizados". De fato, no caso do Rio Grande, para esse período não existem africanos cuja procedência foi Angola, embora, mais para meados do século XVIII, apareçam alguns gentios da Angola nos registros sobreviventes ${ }^{10}$.

Os ardas (ardras, aladas) eram aqueles exportados pelo Reino de Alada, sendo os principais portos de embarque Ofra e Jakin, também na Costa da Mina, conforme Silva Júnior (2016, p. 8-9). Ainda segundo este autor, o termo arda teria perdido força na documentação relativa à Bahia, enquanto o termo mina ter-se-ia popularizado já nas décadas iniciais do século XVIII. No caso do Rio Grande, relevante afirmar que também o termo arda desaparece na documentação paroquial existente, embora Helder Macedo (2013) tenha encontrado um registro para os casos do Seridó, freguesia de Santana, entre 1737 e 1800. Após essa série incompleta de batismos da

10 Como existem poucas series ao longo do século XVIII, tanto de batismo, quanto casamento e óbito, procurou-se trabalhar primeiramente com estes registros entre 1681 e 1714, cujo contexto é, ainda, de construção da capitania e da época da Cuerra dos Bárbaros. 
freguesia de Nossa Senhora da Apresentação, entre 1681 e 1714, os primeiros registros são de matrimônio, a partir de 1727, e o nome arda não aparece mais, dando lugar apenas a minas e angolas.

Já o termo mina acabava englobando de maneira geral os africanos oriundos da Costa da Mina, que seria o modo pelo qual os portugueses se referiam às antigas Costa do Ouro e Costa dos Escravos, região correspondente hoje ao território que vai de Gana até o sudoeste da Nigéria. Tanto ardas como minas eram preferidos nas negociações, uma vez que, comparados aos angolas, eram considerados mais robustos (SILVA JÚNIOR, 2016, p. 9-10).

O comércio atlântico de escravos mostrava oscilações das procedências dos escravos africanos. Para a Bahia, Angola seria o local principal da exportação de escravos até o último quartel do século XVII, enquanto que, para a capitania do Rio de Janeiro, a África Centro Ocidental era o principal porto desde meados do século XVII, que se consolidou ao longo de todo o XVIII (SILVA JÚNIOR, 2016). Também Pernambuco, como a Bahia, teria recebido a maioria de escravos provenientes da Costa da Mina na primeira metade do século XVIII, começando a receber mais angolas nos anos de 1738,1740 , e 1742 em diante, embora ao longo do XVIII houvesse oscilações da região de procedência dos escravos desembarcados em Pernambuco (SILVA \& ELTIS, 2008). Mas de certa forma, os dados do comércio atlântico de escravos de Bahia e Pernambuco coadunam com os números encontrados para o Rio Grande, quando, no período entre 1681 e 1714 , entraram nessa capitania apenas escravos minas e ardas, provenientes da Costa da Mina. Apesar de discordar um pouco dos números levantados por Daniel Silva e David Eltis (2008), o historiador Gustavo Lopes (2012, p. 16) mostra o lento soerguimento da capitania de Pernambuco após a expulsão dos holandeses das Capitanias do Norte, sobretudo nas décadas de 1660 e 1670, assim como uma boa recuperação a partir de 1680, e considera o período entre 1694 e 1704 como de prosperidade econômica de Pernambuco. Este autor também defende que os traficantes de escravos que paravam na Costa da Mina eram provenientes de Lisboa e faziam a rota Lisboa-Costa da Mina-Pernambuco.

Gustavo Lopes (2012) destaca o caso de dois governadores de Pernambuco, João Fernandes Vieira e André Vidal de Negreiros, diretamente vinculados a interesses locais, e exemplos de como a economia açucareira utilizava mão de obrá escrava, que foram nomeados governadores de Angola nos períodos de 1658-1661 e 1661-1666 respectivamente. Esse fato levou muitos angolas para o mercado de escravos de Pernambuco, apesar de esse fluxo não ter permanecido. Portanto, o mercado de escravos de Pernambuco não dependeu de Angola na segunda metade do século XVII e início do XVIIl e, no caso, a Costa da Mina passou a ser o principal fornecedor de escravos. Os dados do Rio Grande confirmam essa informação, caso se leve em consideração 
que os escravos que chegaram ao Rio Grande eram provenientes do porto de Recife (LOPES, 2012, p. 18-21).

Retornando aos dados dos 271 escravos negros, o Gráfico 7 informa como eram constituídas as relações familiares em torno do sistema escravocrata. Com relação ao número desses 271 escravos, os dados foram divididos entre crianças ${ }^{11}$, adultos e ausência de identificação.

Gráfico 7-Relação familiarl, escravos negros na Capitania do Rio Grande, 1681-1714.

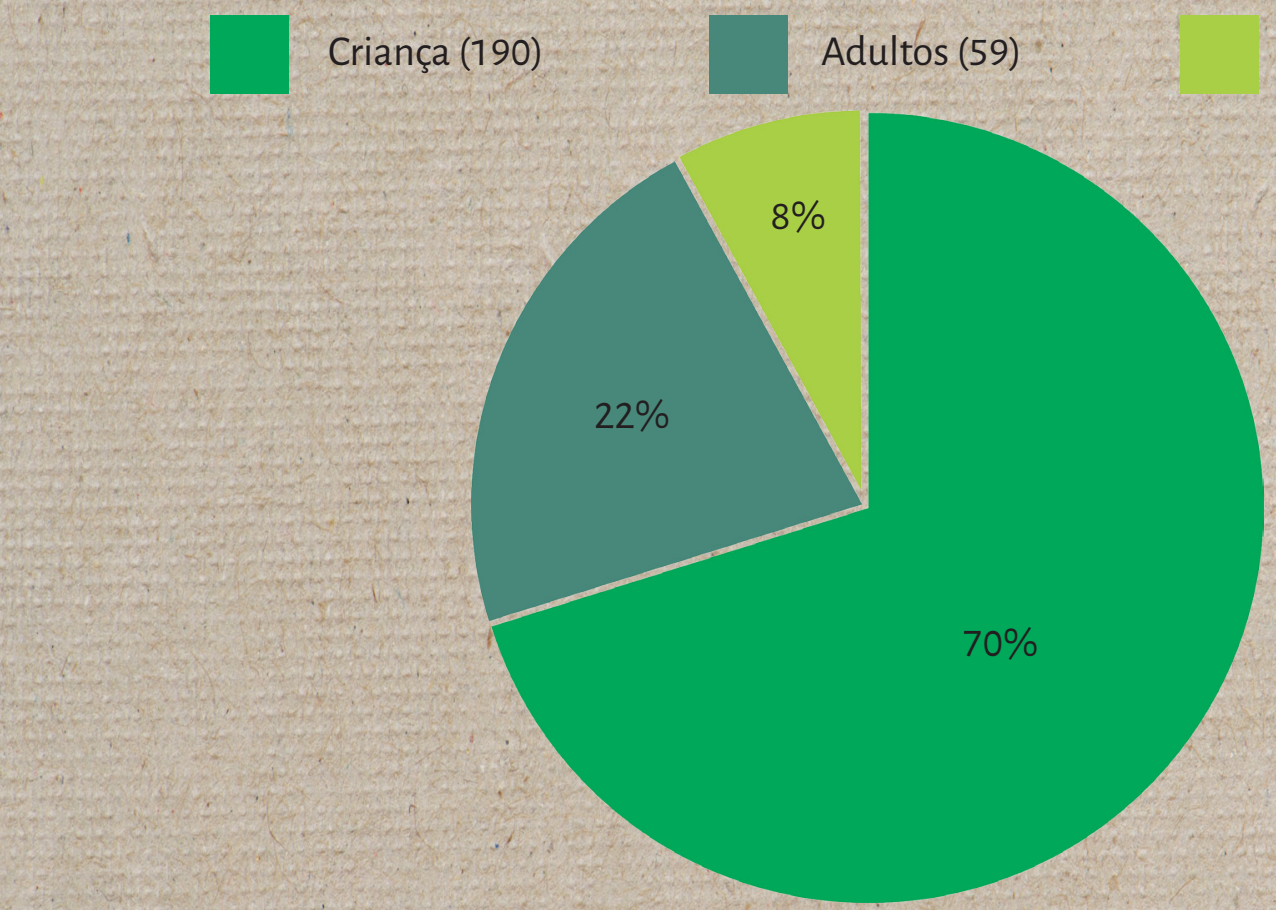

Ausentes (22)

Fonte: Elaborado pelas autoras a partir de dados dos registros paroquiais de batismos da Freguesia de Natal, Riọ Grande do Norte (IAHGP, 1681-1714).

De 271 registros de batismos de escravos negros analisados, 70\% (190) eram batismos de crianças, $22 \%$ de adultos (59) e $8 \%$ de ausentes (22). Esses resultados permitem pensar que a maioria dos batismos era de crianças, e indica que as mulheres escravas estavam reproduzindo, independente das condições impostas pela escravidão. Sobre isso, os próprios senhores incentivavam a reprodução de filhos, pois significava aumento da mão de obra (SLENES, 1999). Os adultos representavam $22 \%$ dos batismos, indicando que o comércio dos escravos provenientes do continente africano na região era existente nesse período e, mais importante, que as famílias do Rio Grande tinham cabedal para adquirir escravos negros, considerados mais caros que os indígenas (SCHWARTZ, 1988).

11 No documento não está escrito que se trata de crianças e não é estabelecida a idade. Mas se pressupôs que fossem batismos de crianças ao analisar a data de batismo e a condição de "filha ou filho" presente no documento, uma vez que, nas Ordenações Filipinas (Livro V, capítulo 99), ficava estabelecido que todos deveriam ser batizados em no máximo um mês após os senhores terem sua posse, e deveriam ter no mínimo 10 anos. As Constituições Primeiras do Arcebispado da Bahia diminuíram essa idade para sete anos, como informado anterioremente. 
Já com relação às 190 crianças escravas negras, os seguintes apontamentos podem ser feitos, com base nos dados apresentados no Gráfico 8.

De 190 registros de batismos de crianças escravas negrae analisados, $78 \%$ (144) eram filhos (as) de mães solteiras, e 22\% (40) com mãe e pai no registro, mas não necessariamente casados perante à Igreja Católica. Entre os dados apontados, é relevante o número de mães escravas negras solteiras que constam nas fontes: 144 , correspondendo a $78 \%$ dos registros.

Gráfico 8-Relação familiarill, crianças de escravos negros na Capitania do Rio Grande, 1687-1714

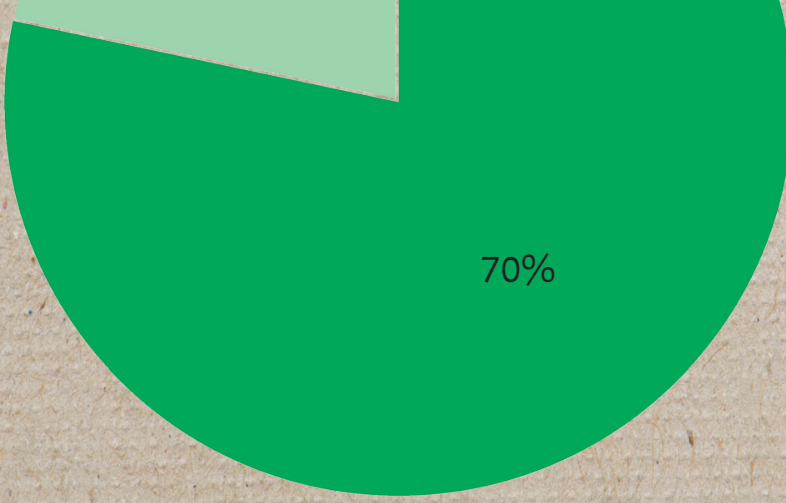

Fonte: Elaborado pelas autoras a partir de dados dos registros paroquiais de batismos da Freguesia de Natal, Rio Crande do Norte (IAHGP, 1681-1714).

Se comparado ao número de registros em que constavam o nome dos pais (40), correspondendo a $22 \%$ dos registros de batismos, tais dados evidenciam um maior número de filhos naturais entre a população negra escravizada. Esse número alto ocorria devido a inúmeros fatores: a) as mulheres negras podiam ter uniões estáveis com homens, mas tais uniões não eram reconhecidas pela Igreja; $b$ ) essas mulheres eram tidas como objeto de relações extraconjugais, sendo muitas vezes violentadas, e não tendo os filhos reconhecidos por seus pais. No entanto, o número de 40 batizados que tinham pai e mãe no registro mostra como, já na retomada do povoamento da capitania do Rio Grande, havia famílias escravas negras, corroborando para os apontamentos feitos por estudos recentes, que desmistificam a promiscuidade dos africanos (MATOSO, 2003 [1982]; SCHWARTZ, 1988; FARIA, 1998; SLENES, 1999). Dessa forma, apesar 
de não ter tido a economia de lavoura de exportação e, portanto, extensa escravaria, a família escrava negra estava presente na construção da sociedade colonial do Rio Grande, evidenciando mais uma vez seu caráter escravista e a escravidão como parte constitutiva dessa sociedade colonial.

Estes dados reforçam que a escravidão fez-se presente desde o início da colonização da capitania do Rio Grande. Desde 1607, quando os jesuítas obtiveram uma sesmaria, já indicavam que traziam consigo quatro escravos negros da guiné, inaugurando a escravidão de origem africana nessa região. No final do século XVII, os dados apresentados mostraram como o instituto da escravidão prosseguiu.

\section{Considerações finais}

Tendo em vista os argumentos a presentados, algumas conclusões acerca da população presente no Rio Grande colonial, no contexto da Guerra dos Bárbaros, podem ser realizadas. No que se refere aos locais de batismos, a distribuição espacial desse sacramento, analisado nos registros, concentra-se na matriz da Freguesia de Nossa Senhora da Apresentação, localizada na cidade de Natal, cuja condição de capital constituiu-se como um dos núcleos de povoamento mais antigos da capitania, junto com o engenho de Cunhaú e os aldeamentos indígenas. Todas essas localidades estavam no litoral, evidenciando uma concentração da população ao longo da costa.

Em relação à condição jurídica, a maioria da população era composta de pessoas consideradas livres. No entanto, $36 \%$ da população era escrava, e mesmo que não tenha sido a base dá mão de obra, ensejando outras relações de trabalho, ainda assim é um número considerável e, portanto, pode-se falar que a sociedade da capitania do Rio Grande era escravista e agia de modo semelhante às outras regiões nas quais a escravidão era mais preponderante.

Dentre os escravizados negros, os trazidos da África vieram da região da Costa da Mina, que fazia parte do golfo da Guiné, e no período estudado foram usadas duas nomenclaturas: gentio de Arda e gentio da Guiné, não sendo identificados escravos pertencentes ao gentio de Angola.

Sobre as relações familiares, chegou-se à constatação de que os dados relativos às mulheres mostram suas relações extraconjugais, ou mesmo o que poderiam ser os filhos resultados da 
violência, uma vez que, ao engravidarem e darem à luz, seus filhos não tinham seus pais reconhecidos. Porém, o número de 40 batizados, filhos naturais, que tinham pai e mãe no registro, mostra também como, já na retomada do povoamento da capitania do Rio Grande, havia famílias escravas negras, uniões às vezes não reconhecidas pela Igreja.

Desta forma, pode-se concluir que, apesar de o Rio Grande não ter tido uma atividade econômica vinculada à exportação, não deixou de utilizar mão de obra escrava em outras atividades. E, embora o elemento indígena tenha sido utilizado como mão de obra escrava, muito em decorrência da própria Cuerra dos Bárbaros, muitos foram os negros escravizados utilizados também como força laboral compulsória, evidenciando que, mesmo não fazendo parte dos grandes lucros da economia açucareira, os moradores do Rio Grande tinham cabedal para possuir escravos negros, e mesmo alguns trazidos da África, considerados mais caros que os indígenas.

Finalmente, o baixo percentual de indígenas batizados indica uma redução significativa da sua população, mas não a completa dizimação dos índios tão apontada pela chamada historiografia clássica (ROCHA POMBO, 1922; LYRA, 1998 [1922]; CASCUDO, 1955), quanto por alguns estudos recentes que salientam a violência da ação dos paulistas na Guerra dos Bárbaros (PUNTONI, 2000). Apesar da ação violenta dos conquistadores, muitas mulheres e crianças indígenas sobreviveram e foram escravizadas em decorrência da guerra.

De modo geral, os dados apontam que as pessoas realizavam o sacramento do batismo, tão importante no período colonial, mesmo em um contexto de incertezas e violentos conflitos; e que os indígenas e negros escravizados poderiam se casar frente à Igreja Católica, bem como batizar seus filhos.

\section{Referências}

ALMEIDA, Maria Regina Celestino de. Metamorfoses indigenas: identidade e cultura nas aldeias coloniais do Rio de Janeiro. Rio de Janeiro: FCV, 2013.

ALVEAL, Carmen Margarida Oliveira. A Anexação da Capitania do Rio Grande em 1701: Estratégia da coroa ou interesse de grupo da Capitania de Pernambuco? In: CAETANO, Antonio Filipe Pereira (Org.). Dinâmicas Sociais, Políticas e Judiciais na América Lusa: Hierarquias, Poderes e Governo (Século XVI-XIX). Recife:UFPE, 2016. p. 135-158. 
Os desafios da governança e as relações de poder na Capitania do Rio Grande na segunda metade do século XVII. In: MACEDO, Helder Alexandre Medeiros de; SANTOS, Rosenilson da Silva (Orgs.). Capitania do Rio Grande: história e colonização na América Portuguesa. João Pessoa: Ideia; Natal: EDUFRN, 2013.p. 27-44.

ALVEAL, Carmen Margarida Oliveira; SILVA, Tyego Franklin da. Nas ribeiras da discórdia: povoamento, políticas de defesa e conflitos na capitania do Rio Grande (1680-1710). In: POSSAMAI, Paulo (Org.). Conquistare defender: Portugal, Países Baixos e Brasil. Estudos de História Militar na Idade Moderna. São Leopoldo: Oikos, 2012. p. 235-249.

CASCUDO, Luís da Câmara. História do Rio Grande do Norte. Rio de Janeiro: Ministério da Educação e Cultura [Serv. de Documentação], 1955.

Nomes da Terra. Natal: Fundação José Augusto, 1968.

CERQUEIRA, César Augusto.; GIVISIEZ, Gustavo Henrique Naves. Conceitos básicos em demografia e dinâmica demográfica brasileira. In: RIOS-NETO, Eduardo Luiz G.; RIANI, Juliana de Lucena (Orgs.). Introdução à demografia da educação. Campinas: Associação Brasileira de Estudos Populacionais, 2004.

CONSTITUIÇÕES DO ARCEBISPADO DA BAHIA. São Paulo: Typografia 2 de Dezembro, 1853 [1707].

COSTA, Renata Assunção da, "Porta do Céu": o processo de cristianização da Freguesia de Nossa Senhora da Apresentação (1681-1714). Dissertação (Mestrado em História) - Universidade Federal do Rio Grande do Norte, Natal. 2015.

DIAS, Patrícia de Oliveira. Onde fica o Sertão rompem-se as águas: processo de territorialização da Ribeira do Apodi-Mossoró (1676-1725). Dissertação (Mestrado em História) - Universidade Federal do Rio Grande do Norte, Natal. 2015.

HEMMING, John. Ouro vermelho. A conquista dos índios brasileiros. São Paulo: Edusp, 2007.

LEMOS, Vicente. Capitães-mores e governadores do Rio Crande do Norte. Rio de Janeiro: Tipografia do Jornal do Comércio, 1912.

LOPES, Fátima Martins. Índios, colonos e missionários na colonização da Capitania do Rio Crande do Norte. Mossoró: Fundação Vingt-un Rosado; Natal: Instituto Histórico e Geográfico do Rio Grande do Norte, 2003.

LOPES, Gustavo Acioli. A Fênix e a conjuntura atlântica: açúcar e tráfico de escravos em Pernambuco na segunda metade do século XVII. Portuguese Studies Review, Peterborough (Canadá), v. 1, n. 20, p.1-35, 2012.

LYRA, Augusto Tavares de. História do Rio Grande do Norte. Natal: EDUFRN, 2008:

KÜHN, Fábio. Um olhar sobre o tráfico negreiro para a colônia do Sacramento a partir dos registros paroquiais (1732-1777). In: ENCONTRO ESCRAVIDÃO E LIBERDADE NO BRASIL MERIDIONAL, 7., 2015, Curitiba. Anais... Curitiba: UFPR, 2015. Disponível em: <http://www.escravidãoeliberdade.com.br/>. Acesso. em: 10 jan. 2017. 
MACEDO, Helder Alexandre Medeiros de. Populações indígenas no sertão do Rio Grande do Norte: história e mestiçagens. Natal: EDUFRN, 2011.

Outras famílias do seridó: genealogias mestiças no sertão do Rio Grande do Norte (séculos XVIII-, -XIX). Tese (Doutorado em História) - Universidade Federal de Pernambuco, Recife. 2013.

MATOSO, Kátia de Queirós. Ser escravo no Brasil. São Paulo: Brasiliense, 2003 [1982.

MELLO, Evaldo Cabral de. Fronda dos Mazombos. Nobres contra mascates: Pernambuco, 1666-1715. São Paulo: 34, 2003.

Olinda Restaurada. Cuerra e açúcar no Nordeste, 1630-1654. São Paulo: 34, 2007.

Rubro Veio. O imaginário da restauração pernambucana. São Paulo: Alameda, 2008.

MONTEIRO, John. Negros da terra: índios e bandeirantes nas origens de São Paulo. São Paulo: Companhia das Letras, 1994.

MORAIS, Ana Lunara da Silva. Entre veados, carneiros e formigas: conflito pela posse de terra na ribeira do Ceará-Mirim, e concepções de mentalidade possessória, 1725-1761. 2014. Dissertação (Mestrado em História) - Universidade Federal do Rio Grande do Norte, Natal. 2014.

OLIVEIRA, João Pacheco. A viagem de volta: etnicidade política e reelaboração cultural no Nordeste indígena. Rio de Janeiro: Laced, 2004.

PERRONE-MOISÉS, Beatriz. Índios livres e índios escravos: os princípios da legislação indigenista do período colonial (séculos XVI-XVIII). In: CUNHA, Manuela Carneiro da (Org.). História dos índios no Brasil. São Paulo: Companhia das Letras, 1992. p. 115-132.

PIRES, Maria Idalina da Cruz. Guerra dos Bárbaros: resistência indígena e conflitos no nordeste colonial. Recife: UFPE, 1990.

PUNTONI, Pedro. A Cuerra dos Bárbaros: povos indígenas e a colonização do sertão Nordeste do Brasil, 1650-1720. São Paulo: Hucitec, 2000.

ROCHA POMBO. História do Rio Grande do Norte. Rio de Janeiro: Editores Annuário do Brasil, 1922.

SCHWARTZ, Stuart. Segredos internos: engenhos e escravos na sociedade colonial (1535-1835). São Paulo: Companhia das Letras, 1988.

SHRYOCK, Henry S.; SIEGEL, Jacob Stuart. The methods and materials of demography. San Diego: Academic Press, 1976. 
SCOTT, Ana Silvia Volpi; SCOTT, Dario. Cruzamento Nominativo de Fontes: desafios, problemas e algumas reflexões para a utilização dos registros paroquiais. In: ENCONTRO NACIONAL DE ESTUDOS DE POPULAÇÃO, 15., 2006, Caxambu. Anais...Caxambu: ABEP, 2006. p 1-14. Disponível em: <http://www. abep.org.br/publicacoes/index.php/anais/article/view/1669/1630>. Acesso em: nov. 2017.

Análise quantitativa de fontes paroquiais e indicadores sociais através de dados coletados para sociedades do Antigo Regime. Mediações-Revista de Ciências Sociais, Londrina, v. 18, n. 1, p. 106-124, jan./ jul. 2013. Disponivel em: <http://www.uel.br/revistas/uel/index.php/mediacoes/article/view/16474>. Acesso em: nov. 2017.

SILVA, Daniel Barros Domingues da; ELTIS, David. The slave trade to Pernambuco, 1561-1851. In: ELTIS, David; RICHARDSON, David (Orgs.). Extending the frontiers: essays on the new Transatlantic Slave Trade Database. New Haven; Londres: Yale University Press, 2008. p. 95-129.

SILVA, Tyego Franklin da. A ribeira da discórdia: terras, homens e relações de poder na territorialização do Assu colonial (1680-1720). Dissertação (Mestrado em História) - Universidade Federal do Rio Grande do Norte, Natal. 2015.

SILVA JÚNIOR, Carlos da. Ardras, minas e jejes, ou escravos de "primeira reputação": políticas africanas, tráfico negreiro e identidade étnica na Bahia do século XVIII. Almanack, Guarulhos, n. 12, p. 6-33, 2012. Disponivel em: <http://www.scielo.br/pdf/alm/n12/2236-4633-alm-12-00006.pdf>. Acesso em: nov. 2017.

SLENES, Robert W. Na senzala, uma flor: esperanças e recordações na formação da família escrava-Brasil, Sudeste, século XIX. Rio de Janeiro: Nova Fronteira, 1999.

SLENES, Robert; FARIA, Sheila de Castro. Família escrava e trabalho. Revista Tempo, Rio de Janeiro, v. 3 , n. 6, dez. 1998. Disponível em: <http://www.historia.uff.br/tempo/artigos_dossie/artg6-4.pdf>. Acesso em: nov. 2017.

SOARES, Carlos Eugênio Líbano. "Instruído na fé, batizado em pé": batismo de africanos na Sé da Bahia na primeira metade do século XVIII, 1734-1742. Afro-Ásia, Salvador, n. 39, p. 79-113, 2010. Disponível em: <https://repositorio.ufba.br/ri/bitstream/ri/3575/1/AA 39 CELSoares.pdf>. Acesso ém: nov. 2017.

SOARES, Mariza de Carvalho. Devotos da cor; identidade étnica, religiosidade e escravidão no Rio de Janeiro, século XVIII. Rio de Janeiro: Civilização Brasileira, 2000.

TAUNAY, Afonso d'Escragnolle. (1930). A guerra dos bárbaros. 2. ed. Mossoró: Fundação Vingt-Un Rosado; ETFRN, 1995

TORRES-LONDOÑO, Fernando. A outra família. Concubinato, Igreja e escândalo na colônia. São Paulo: Loyola, 1999.

TRASLADO do Auto de Repartição de Terras do Rio Grande. Revista do Instituto Historico e Ceographico do Rio Crande do Norte, Natal, v. 7, n. T e 2, p. 5-131, 1909. 
